\section{Respiratory muscle strength and quality of life in chronic kidney disease patients undergoing hemodialysis}

\author{
Força muscular respiratória e \\ qualidade de vida em pacientes \\ com doença renal crônica \\ submetidos à hemodiálise
}

Juliana de Souza da Silva (D)

Tamara Silva de Sousa (D)

Caroline de Fátima Ribeiro Silva (D)

Fernanda Siqueira (D)

Tatiana Onofre (D)

Universidade Federal do Amapá (UNIFAP), Department of Biological Sciences and Health, Physiotherapy Course, Cardiovascular and Respiratory Physiotherapy Laboratory, Macapá, AP, Brazil

Date of first submission: December 30, 2020

Last received: March 28, 2021

Accepted: May 11, 2021

Associate editor: Janice Luisa Lukrafka Tartari

*Correspondence: tatianaonofre@hotmail.com

\begin{abstract}
Introduction: Hemodialysis (HD) sessions associated with the chronic kidney disease (CKD) repercussions may cause respiratory muscle impairment and limitations of daily living activities, which may compromise the quality of life. Objective: To evaluate respiratory muscle strength and quality of life in HD patients. Methods: A cross-sectional study involving CKD patients of both sexes undergoing $H D$. All were evaluated during HD, using an evaluation form containing personal and clinical data, presence of comorbidities, lifestyle (including self-reported physical activity) and vital signs. Respiratory muscle strength was analyzed by maximum inspiratory (MIP) and maximum expiratory (MEP) pressures by manovacuometer and quality of life using the SF-36 questionnaire. Results: Sixty-eight patients were evaluated (69.1\% men), with a mean age of $54.9 \pm 13.6$ years. The MEP\% was below of predicted $(79.5 \pm 25.7)$ and the MIP\% was reduced only in women $(77.8 \pm 38.7)$. The MIP\% was related to CKD time $(p=0.04)$ in men. The SF-36 domain that showed the most impairment was physical limitation [25.0 (13.0-67.0)], while mental health was the least impaired domain [72.0 (62.0-84.0)]. Those who reported the practice of physical activity obtained better results in vitality domain $(p=0.01)$. In the analysis stratified by sex, the functional capacity domain was less compromised in men who practiced selfreported physical activity $(p=0.02)$. Conclusion: $C K D$ patients undergoing HD had a reduction in MEP relative to predicted, in addition to a greater impairment of MIP in men with longer CKD time and in women alone, although the clinical relevance of this finding is uncertain. Quality of life was more compromised in the physical limitation domain, where those who self-reported physical activity achieved better results in the domains of vitality (total sample) and functional capacity (men).
\end{abstract}

Keywords: Chronic kidney failure. Renal dialysis. Respiratory muscles. Maximum respiratory pressures. Quality of life. 


\section{Resumo}

Introdução: As sessões de hemodiálise (HD) associadas às repercussões da doença renal crônica (DRC) podem causar comprometimento muscular respiratório e limitações das atividades de vida diária, o que pode comprometer a qualidade de vida. Objetivo: Avaliar a força muscular respiratória e a qualidade de vida em pacientes em HD. Métodos: Estudo transversal envolvendo pacientes de ambos os sexos com DRC submetidos à HD. Todos foram avaliados durante a HD, por meio de uma ficha de avaliação contendo dados pessoais e clínicos, presença de comorbidades, hábitos de vida (incluindo a prática de atividade física autorreferida) e sinais vitais. A força muscular respiratória foi analisada pelas pressões inspiratória máxima (PImáx) e expiratória máxima (PEmáx) por meio do manovacuômetro e a qualidade de vida através do questionário SF-36. Resultados: Foram avaliados 68 pacientes $(69,1 \%$ homens), com idade média de 54,9 \pm 13,6 anos. O \%PEmáx foi abaixo do predito $(79,5 \pm 25,7)$ e o \%PImáx foi reduzido apenas em mulheres $(77,8 \pm 38,7)$. Nos homens, a \%PImáx foi relacionada ao tempo de DRC $(p=0,04)$. O domínio do SF-36 que apresentou maior comprometimento foi a limitação física $[25,0(13,0-67,0)]$, enquanto a saúde mental foi o domínio menos prejudicado $[72,0(62,0-84,0)]$. Aqueles que relataram a prática de atividade física obtiveram melhores resultados no domínio vitalidade $(p=0,01)$. Na análise estratificada por sexo, o domínio capacidade funcional foi menos comprometido nos homens que praticavam atividade física autorrelatada $(p=0,02)$. Conclusão: Pacientes com DRC submetidos à HDe apresentaram redução na PEmáx em relação ao predito, além de maior comprometimento da PImáx nos homens com maior tempo de DRC e nas mulheres isoladamente, apesar da relevância clínica desse achado ser incerta. A qualidade de vida foi mais comprometida no domínio limitação física, onde aqueles que relataram praticar atividade física obtiveram melhores resultados nos domínios vitalidade (amostra total) e capacidade funcional (homens).

Palavras-chave: Insuficiência renal crônica. Diálise renal. Músculos respiratórios. Pressões respiratórias máximas. Qualidade de vida.

\section{Introduction}

Chronic kidney disease (CKD) is characterized by changes that result in continuous and irreversible loss of renal structure and function, as a consequence of nephron destruction for three months or more, regardless of clinical diagnosis, and has been associated with high mortality rates worldwide. ${ }^{1,2}$ As the disease progresses, the glomerular rate decreases and the kidneys are unable to maintain body homeostasis, leading to renal failure within a few months; replacement therapy is required, subject to the use of artificial blood filtration methods such as hemodialysis, which has increased the survival of this population. ${ }^{3}$

Despite the benefits, negative impacts have been attributed to dialysis treatment, which when associated with the repercussions of CKD further compromise the clinical status of patients, which may result in changes in calcium and phosphorus metabolism, functionality, independence, well-being and social life, which tend to be worsen as the disease progresses. ${ }^{4,5}$ In addition, several systems may also be affected, including the respiratory and musculoskeletal systems, when compared to the general population. ${ }^{2}$

Multiple factors have been attributed as an explanation for the occurrence of musculoskeletal structure abnormalities in CKD patients undergoing hemodialysis, such as uremic myopathy, deficit in muscle oxygenation, decrease in muscle ATP synthesis, modification of glycolytic enzymes, low fatty acid oxidation and changes in muscle proteins, which may compromise the peripheral and respiratory muscles. ${ }^{6,7}$ Thus, the function and respiratory mechanics impacts may result in ventilatory deficit and decreased lung capacity, with consequent respiratory diseases development which may also result from the possible respiratory muscles degradation. ${ }^{7,8}$

The loss of muscle mass associated with a transverse area and grouping of muscle fibers reduction, which are considered admissible influencers of respiratory muscle deterioration, may be related to the development of dyspnea and low exercise tolerance, making these patients susceptible to evolve with gradual decline in respiratory system integrity. ${ }^{6,9}$ In this context, patients undergoing hemodialysis often have limitations in performing their activities of daily living, either due to dyspnea or physical tiredness due to the intense treatment routine. ${ }^{9}$ Associated with possible cardiorespiratory and musculoskeletal damage, these patients are to be affected by a vicious cycle of physical inactivity, and consequently muscle weakness and functional limitation. ${ }^{4}$

Another factor is that once patients are inserted in dialysis treatment, they must comply with a series of 
recommendations which involve care with the access route for the dialysis and reduced weight supported by the limbs, which limits the tasks performed at home, ${ }^{10}$ unfavorably contributing to the quality of life. Impaired quality of life has been related to a greater decline in the respiratory system and above all to the lack of respiratory muscle strength. ${ }^{2,6}$ The progressive damage caused to the muscular system as a result of the various disorders involving the disease and dialysis treatment become major limiting factors for CKD patients, and may directly or indirectly affect their physical, functional and psychological performance. ${ }^{4,5}$ When added to other previous conditions arising from CKD, these consequences are associated with mortality and increased disability rates among chronic renal patients, being an indicator of greater health problems in these patients. $^{11}$

However, despite being considered a public health problem worldwide and the negative effects of CKD being well defined, the real impairment of patients undergoing hemodialysis in relation to respiratory muscle strength and information on specific domains of quality of life, such as functional capacity, physical limitations, emotional aspects, and mental health, especially in the northern region of Brazil, are still unclear. Although there are other studies in this sense, the results in relation to the values of MIP and MEP are still conflicting with the existence of gaps on potential factors that may influence (or not) the deterioration of respiratory muscle strength, mainly due to the sample heterogeneity of these studies.

The main objective of this study, therefore, was to evaluate respiratory muscle strength and quality of life in CKD patients undergoing hemodialysis. As hypotheses, we believe that these patients have a reduction in maximum respiratory pressures in relation to the predicted and impaired in quality of life, especially in its physical aspects.

\section{Methods}

This is an observational cross-sectional study conducted at the Nephrology Unit of a public hospital in the state of Amapá, Brazil, considered a reference center for the chronic kidney disease population in the region. The research complied with the standards for research with human beings of the National Health Council and was approved by the Ethics and Research Committee of the Universidade Federal do Amapá (2.615.142). Participants were informed about the research and signed the Informed Consent Form.

The sample size calculated was at least 68 patients, resulting from a previous study $(n=27),{ }^{4}$ using the SF36 domain "functional capacity" (57.5 \pm 24.2$)$ as an outcome variable, considering a margin of error of $5 \%$ to obtain estimates, level of confidence interval of $95 \%$ and with an increase of $10 \%$, referring to possible sample losses. The following formula was used for the sample calculation: $n=(Z \alpha / 2 \times \delta / E)^{2}$, where $Z \alpha / 2=$ critical value for the desired degree of confidence, usually: 1.96 (95\%); $\delta=$ population standard deviation of the variable; $\mathrm{E}=$ standard error, usually $\pm 5 \%$ of the mean $(1.05 \times$ mean $) .^{12}$

Patients with a medical diagnosis of CKD under outpatient hemodialysis treatment of both sexes and under medical follow-up were included. Exclusion criteria included: those below 18 years of age; presence of double lumen catheter as hemodialysis route; cognitive and/or neurological changes which would interfere with the instructed techniques; diagnosis of chronic obstructive pulmonary disease (COPD), uncontrolled asthma, tuberculosis, pulmonary fibrosis, systemic lupus erythematosus, neuromuscular disease, untreated abdominal hernia and/or cardiovascular disease such as unstable angina, chronic heart failure and acute arrhythmias; postoperative period of recent upper airway, chest or abdomen surgery or trauma; pregnant women and the need for urgent surgical intervention.

\section{Evaluation procedures}

Patients were evaluated during hemodialysis and 60 minutes after the beginning of the second session of the week. For data collection an evaluation form was used containing personal and clinical data (age, sex, urea and creatinine values, length of disease and time on dialysis, weight, height, and body mass index), information on the presence of comorbidities, lifestyle habits (alcoholism, smoking, and self-reported physical activity), vital signs (blood pressure, heart rate, and peripheral oxygen saturation), in addition to respiratory muscle strength and quality of life, which represent the primary outcomes of the study. When asked about the practice of physical activity, those patients who reported performing at least 150 minutes of moderate-intensity aerobic activity or 75 minutes of high-intensity aerobic activity were considered active. ${ }^{13}$ In the presence of some clinical 
(i.e., dizziness, nausea, pain, severe cramps, etc.) or hemodynamics instability (hypoxemia or tachycardia and hypertension uncontrolled), the procedures were interrupted, and the patients were reassessed in the next session. All procedures were standardized and performed by previously trained researchers.

Respiratory muscle strength was assessed by measuring maximal inspiratory pressure (MIP) and maximal expiratory pressure (MEP) using an analog manovacuometer (WIKA - MV 150, Brazil). All patients used disposable nasal clips and mouthpieces and were comfortably seated. MIP was measured at residual volume level and MEP from total lung capacity, for which efforts were repeated three times, with a rest of 60 seconds for each measurement, with the highest value being considered with a maximum variation of $10 \%$ between three measurements taken. A maximum of five measurements were respected, recording the highest value of all. ${ }^{14}$ The predicted MIP and MEP values for the patients was calculated considering the equation described by Neder et al. ${ }^{15}$

The Brazilian version of the Medical Outcomes Study 36- Item short- Form Health Survey (SF-36) quality of life questionnaire was used. ${ }^{16}$ Eight domains were evaluated: functional capacity, limitation by physical aspects, pain, general health, vitality, social aspects, emotional aspects and mental health, where the score ranged from 0 a 10 in which the highest score reflects better quality of life.

\section{Statistical analysis}

Data analysis was performed using the Statistica 10.0 software (StatSoft, USA) using the Shapiro-Wilk Normality Test, and the data were subsequently expressed as mean and standard deviation and as median and interquartile range (25 - 75\%). Frequency tables were generated for categorical variables. Spearman's correlation coefficients were calculated to examine the strength of the relationship between non-parametric quantitative variables. Student's t-test and Mann-Whitney $U$ test were used to compare parametric and non-parametric variables between sexes, respectively. We performed a stratified analysis of CKD time based on the minimum, percentile (25\%, 50\% and $75 \%$ ) and maximum values, where four subgroups of periods were considered: 6 to $22 ; 23$ to $54 ; 55$ to 102 ; and 103 to 564 months. Oneway analysis of variance (ANOVA) and post-hoc Tukey test were performed to compare the mean maximum respiratory pressures between CKD time and dialysis time categories, and CKD with the SF-36 domains. A significance level of $5 \%$ was established for all analyzes.

\section{Results}

Of the 175 patients recruited, 107 were excluded for the following reasons: presence of double-lumen catheter $(n=98)$ or associated diseases such as heart failure $(n=3)$, neuromuscular disease $(n=2)$, abdominal hernia ( $n=1)$, recent post-operative abdominal surgery $(n=1), \operatorname{COPD}(n=1)$ and acute arrhythmia $(n=1)$. Thus, 68 patients were considered for the study.

The sample was predominantly male $169.1 \% ; n=$ $47)$, age $54.9 \pm 13.6$ years, with CKD diagnosis time of 54.0 (22.0 - 102.0) months and dialysis time equivalent to 25.5 (13.0 - 67.0) months, with no difference between sexes for these variables. The main comorbidities observed were systemic arterial hypertension (85.2\%) and diabetes (41.17\%). Regarding lifestyle, most patients were sedentary (86.7\%), and those who reported physical activity (13.3\%) predominantly performed aerobic activities such as walking, soccer and dance. Half of the population were former smokers (50.0\%) (Table 1 ).

Regarding respiratory muscle strength, patients had MIP values close to the predicted $(84.1 \pm 33.3 \%)$, but with MEP below $80 \%$ of the predicted (79.5 $\pm 25.7 \%$ ). In the analysis by sex, inspiratory and expiratory muscle strength were reduced in women $(77.8 \pm 38.7 \%)$ and men $(79.1 \pm 23.0 \%)$, respectively, but without statistical difference when compared with the opposite sex (Table 2 ). In men, when performing the analysis stratified by months of CKD time, a lower \% predicted MIP was found in those with longer CKD time $(p=0.04)$ (Figure 1). With this result, we can suggest that in men with CKD time less than 103 months it may not be enough to generate impairment in \%MIP, however, after 103 months, an important reduction was observed in the values founds of \%MIP.

When evaluating quality of life, it was reduced in the physical limitation domain in both sexes, with a median of 25.0 (0.0 - 75.0) points, but with greater impairment among men $(p=0.02)$. The second domain with the lowest score was health status with 52.0 (40.0 - 62.0) points, and the domain with the best quality of life was mental health with 72.0 (62.0 - 84) points, both without statistical difference between sexes (Table 2). 
Table 1 - Characteristics of the study population regarding demographic, clinical and anthropometric aspects

\begin{tabular}{|c|c|c|c|c|}
\hline Variables & Total $(n=68)$ & Men $(n=47)$ & Women $(n=21)$ & ${ }^{*} p$-value \\
\hline Age (years) & $54.9 \pm 13.6$ & $55.8 \pm 13.8$ & $52.8 \pm 13.2$ & 0.84 \\
\hline CKD time (months) & $54.0(22.0-102.0)$ & $36.0(17.0-120.0)$ & $66.0(24.0-96.0)$ & 0.39 \\
\hline Dialysis time (months) & $25.5(13.0-67.0)$ & $27.0(12.0-60.0)$ & $22.0(13.0-72.0)$ & 0.92 \\
\hline $\mathrm{SBP}(\mathrm{mmHg})$ & $150.0(135.0-160.0)$ & $150.0(140.0-160.0)$ & $150.0(130.0-160.0)$ & 0.91 \\
\hline $\mathrm{DBP}(\mathrm{mmHg})$ & $80.0(80.0-90.0)$ & $80.0(80.0-90.0)$ & $80.0(80.0-90.0)$ & 0.79 \\
\hline Weight (kg) & $67.4 \pm 13.9$ & $69.7 \pm 13.4$ & $62.1 \pm 14.0$ & 0.03 \\
\hline Height (m) & $1.61 \pm 0.10$ & $1.64 \pm 0.08$ & $1.53 \pm 0.09$ & $<0.01$ \\
\hline $\operatorname{BMI}\left(\mathrm{kg} / \mathrm{m}^{2}\right)$ & $25.7 \pm 4.1$ & $25.5 \pm 3.4$ & $26.3 \pm 5.6$ & 0.48 \\
\hline Sedentary & $59.0(86.7 \%)$ & $40.0(85.1 \%)$ & $19.0(90.4 \%)$ & 0.73 \\
\hline Physical activity & $9.0(13.3 \%)$ & $7.0(14.9 \%)$ & $2.0(9.5 \%)$ & 0.74 \\
\hline Hipertension & $58.0(85.2 \%)$ & 40.0 (85.1\%) & $18.0(85.7 \%)$ & 0.96 \\
\hline Ex-smoker & $34.0(50.0 \%)$ & $25.0(53.1 \%)$ & $9.0(42.0 \%)$ & 0.50 \\
\hline Pack-years smoking & $5.1(1.2-20.0)$ & $6.0(2.1-20.0)$ & $1.4(0.3-18.0)$ & 0.31 \\
\hline Diabetes & $28.0(41.1 \%)$ & $19.0(40.4 \%)$ & $9.0(42.8 \%)$ & 0.87 \\
\hline Urea (mg/dL) & $141.4 \pm 41.3$ & $148.0 \pm 41.2$ & $126.7 \pm 37.2$ & 0.04 \\
\hline Creatinine (mg/dL) & $10.1 \pm 3.5$ & $11.0 \pm 3.6$ & $8.2 \pm 2.3$ & $<0.01$ \\
\hline
\end{tabular}

Note: Data are shown as mean \pm standard deviation, median (interquartile range $25-75 \%$ ) and $n(\%)$. CKD = chronic kidney disease; SBP = systolic blood pressure; DBP = diastolic blood pressure; BMI = body mass index. *Student's t-test for parametric variables and Mann-Whitney $U$ test for nonparametric variables.

Table 2 - Evaluation of respiratory muscle strength and analysis of the domains of the SF-36 quality of life questionnaire of the study population

\begin{tabular}{lcccc}
\hline Variables & Total $(\mathbf{n}=\mathbf{6 8})$ & Men $(\mathbf{n}=\mathbf{4 7})$ & Women $(\mathbf{n}=\mathbf{2 1})$ & ${ }^{*} \mathbf{p}$-value \\
\hline MIP obtained $\left(\mathrm{cmH}_{2} \mathrm{O}\right)$ & $88.5 \pm 38.6$ & $98.1 \pm 36.7$ & $66.9 \pm 34.4$ & $<0.01$ \\
\%predicted $\mathrm{MIP}$ & $84.1 \pm 33.3$ & $86.9 \pm 30.7$ & $77.8 \pm 38.7$ & 0.30 \\
MEP obtained $\left(\mathrm{cmH}_{2} \mathrm{O}\right)$ & $87.9 \pm 32.8$ & $96.5 \pm 31.0$ & $68.8 \pm 29.1$ & $<0.01$ \\
\%predicted MEP & $79.5 \pm 25.7$ & $79.1 \pm 23.0$ & $80.6 \pm 31.6$ & 0.82 \\
Functional capacity & $67.5(40.0-80.0)$ & $70.0(45.0-85.0)$ & $55.5(30.0-70.0)$ & $<0.01$ \\
Physical limitation & $25.0(0.0-75.0)$ & $24.0(0.0-100.0)$ & $25.5(0.0-25.0)$ & 0.02 \\
Pain & $61.0(41.0-95.0)$ & $61.0(41.0-74.0)$ & $62.0(41.0-100.0)$ & 0.74 \\
Health status & $52.0(40.0-62.0)$ & $52.0(42.0-62.0)$ & $52.0(35.0-60.0)$ & 0.33 \\
Vitality & $65.0(55.0-70.0)$ & $65.0(55.0-70.0)$ & $60.0(55.0-75.0)$ & 0.90 \\
Social aspects & $68.7(50.0-87.5)$ & $75.0(50.0-87.5)$ & $62.5(50.0-87.5)$ & 0.82 \\
Emotional aspects & $66.6(33.3-100.0)$ & $66.6(3.3-100.0)$ & $66.6(33.3-66.6)$ & 0.15 \\
Mental health & $72.0(62.0-84.0)$ & $76.0(64.0-92.0)$ & $68.0(60.0-80.0)$ & 0.15 \\
\hline
\end{tabular}

Note: Data are displayed as mean \pm standard deviation and median (interquartile range $25-75 \%$ ). MIP = maximum inspiratory pressure; MEP = maximal expiratory pressure. *Student's t-test for parametric variables and Mann-Whitney $U$ test for non-parametric variables. 


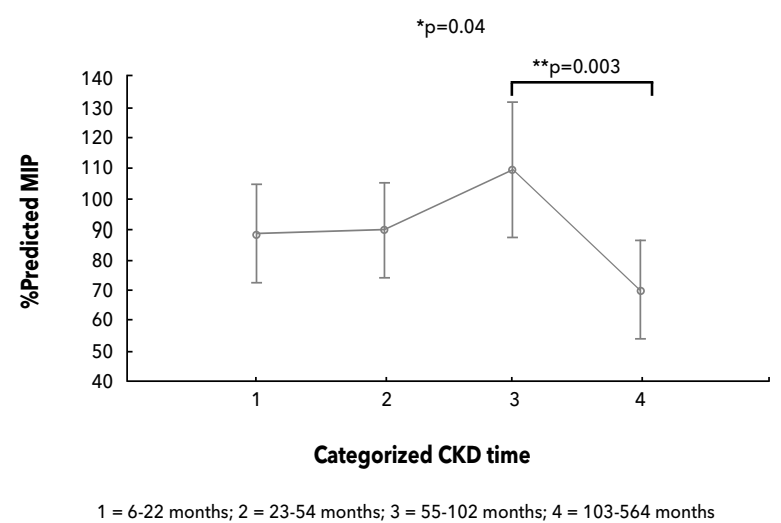

Figure 1 - Comparison between time categories of chronic kidney disease and MIP\% in male subjects $(n=47)$. MIP = maximum inspiratory pressure; $C K D=$ chronic kidney disease. *One-way ANOVA, **Post-hoc Tukey Test.
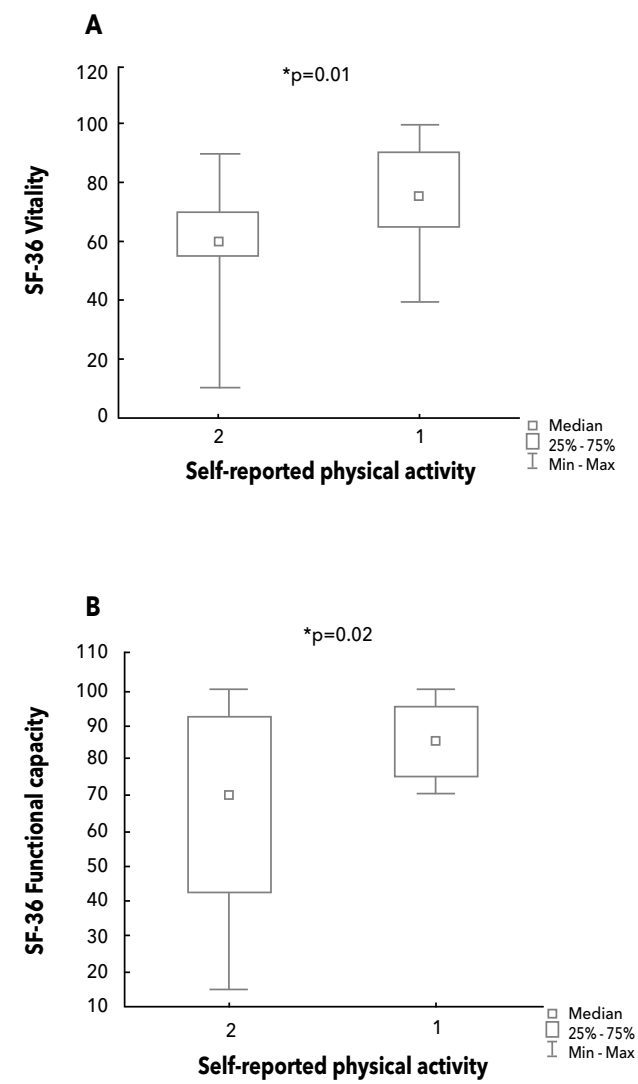

Figure 2 - Comparisons between self-reported physical activity practice and SF-36 domains. A: Comparison between physical activity and vitality for total sample $(n=68)$; B: Comparison between physical activity and functional capacity for men ( $n=47) .1$ = Does physical activity; $2=$ Does not perform physical activity. ${ }^{\star}$ Mann-Whitney $\cup$ Test.
By analyzing the relationship between self-reported physical activity practice and some quality of life domains, we found significant comparisons with the vitality $(p=0.01)$ domain for total sample, showing that patients who performed physical activity presented better quality of life in this domain. In the analysis stratified by sex, we observed that the men who practiced self-reported physical activity had higher scores in the functional capacity domain ( $p=0.02)$, reflecting better quality of life in this aspect (Figure 2).

\section{Discussion}

Our findings showed that expiratory muscle strength was reduced relative to predicted in a sample of CKD patients undergoing hemodialysis, and quality of life was more compromised in the physical limitation domain. In the analysis by sex, we observed MEP and MIP values below $80 \%$ of the predicted in both men and women, respectively, although the clinical relevance of these findings is uncertain. Associated factors such as CKD time and self-reported physical activity practice showed to be possible influences on inspiratory muscle strength in men and in the functional capacity and vitality domains, respectively.

It is known that hemodialysis treatment can trigger numerous repercussions for the body, such as decreased functionality and respiratory muscle strength. ${ }^{17}$ The real causes of these injuries are still not well understood, but their pathogenesis is believed to be similar to the mechanisms that affect the peripheral muscles. ${ }^{18}$ Some pathophysiological explanations can be considered as hypotheses for respiratory muscle strength deterioration in these patients such as systemic inflammation, electrolyte changes, structural changes in cell morphology, impaired mitochondrial function, hypotrophy, and above all as a result of uremic myopathy. ${ }^{19,20}$

Few studies have evaluated respiratory muscle strength at the same time as our study, i.e., during hemodialysis. Therefore, some variability in these results has been observed according to the evaluated moments. Previously in comparing the mean respiratory muscle strength found with the predicted value, Jatobá et al. ${ }^{21}$ showed a reduction of $38.2 \%$ for MIP and $29.0 \%$ for MEP in 27 chronic renal patients evaluated during hemodialysis. In contrast, the population of our study 
showed a reduction of $15.9 \%$ and $20.5 \%$ for MIP and MEP, respectively, showing lower impairment of these variables. We believe that some hypotheses may justify the difference of these findings. First, the average dialysis time of the patients in the present study was less (25.5 versus 44.3 months). Second, we excluded all patients with systemic lupus erythematosus and/or chronic cardiovascular and respiratory diseases, unlike Jatobá et al., ${ }^{21}$ who in their sample included patients with COPD, cardiomyopathy, lupus and ischemic stroke, in addition to also presenting smoking patients (12\% versus $0 \%$ in present study), where we believe that these are potential factors that may influence the greater impairment of respiratory muscle strength. Our findings corroborate with the study by Figueiredo et al., ${ }^{5}$ which showed a $16.0 \%$ decrease for MIP in a sample of 65 patients evaluated immediately before the hemodialysis session, but its population was more similar to ours, both in relation to the sample size, regarding the time of dialysis and the presence of comorbidities. Rocha and Araújo $^{19}$ found a slight increase in MIP when analyzing the acute effects of hemodialysis after the session ( $p=0.04$ ), from $67.5 \%$ (pre) to $73.2 \%$ (post) of the predicted value, demonstrating that hemodialysis seems to exert immediate effects which provide better respiratory muscle performance. However, it is not yet known whether respiratory muscle strength assessed during hemodialysis may change significantly compared to the pre- or post-immediate time.

It is also believed that the respiratory muscle strength of CKD patients may present greater longterm losses in those who undergo renal replacement therapy, which may be related to greater severity of the disease. We identified a significant relationship ( $p=0.04$ ) of lower MIP\% in men with longer disease duration when comparing different categories of CKD time in our study, however there was no relationship with hemodialysis time. Even with a sample presenting a dialysis time of 34.1 months (higher than our findings), Fassbinder et al. ${ }^{4}$ also found no significant correlation between hemodialysis time and MIP. However, when evaluating 17 patients with an average dialysis time of 27.0 months (close to the 25.5 months observed in our study), Kovelis et al. ${ }^{22}$ found a negative and significant correlation of MIP $(r=-0.53)$ and MEP $(r=-0.63)$ with hemodialysis time. Thus, it is assumed that not only the treatment duration but also the degree of health impairment of these patients may reflect on respiratory muscle strength. It is important to highlight that, except for Jatobá et al., ${ }^{21}$ the evaluations in the other studies mentioned above were performed in periods when patients were not undergoing dialysis. Given this, it is clear that the heterogeneity of studies regarding the assessment moment of respiratory muscle strength and population studied profile can be an influencing factor in the outcome of this variable.

We know that the assessment of respiratory muscle strength is not yet a routine in dialysis services, including the center where this study was developed. As previously mentioned, the majority of dialysis patients are vulnerable to loss of muscle mass (including respiratory muscles), however, the possible chronic pulmonary repercussions resulting from dialysis treatment are still little known and can vary according to each population. We believe that the inclusion of the evaluation of MIP and MEP measurements during hemodialysis can be important in clinical practice, because once weakness is identified, especially of inspiratory muscles, it will be useful for the prescription of personalized and individualized intradialytic exercises, such as during inspiratory muscle training, ${ }^{23-26}$ considering that patients spend at least 4 hours of their day (three times a week) performing the hemodialysis session.

It is noteworthy that dialysis treatment, although contributing to the life expectancy of CKD patients, can negatively affect their quality of life, as it favors sedentary lifestyle and functional decline. In this sense, Fassbinder et al. ${ }^{4}$ and Broers et al. ${ }^{27}$ obtained results similar to ours, revealing that the domains of the most compromised quality of life questionnaire were those related to the physical component. Wyld et al. ${ }^{28}$ recently revealed that physical capacity presents greater impairment compared to emotional aspects through an analysis of 1,112 CKD patients, while being influenced by disease progression.

It is true that CKD patients see changes in their body composition, which predispose them to low metabolic activity, inadequate physiological performance, impairment of organs and systems such as the musculoskeletal system (which is one of the most affected), ${ }^{29}$ which may be related to the reduction in their physical capacity to perform usual daily tasks. ${ }^{27,30}$ These changes are likely to be potentiated for patients undergoing dialysis treatment, and may be associated with aging, neuropathies, increased body fat, anemia, myopathies, ${ }^{29}$ tiredness, stiffening of the joints, muscle 
cramps and pain. ${ }^{31,32}$ These aspects, also associated with the presence of arteriovenous fistula or catheter, are directly associated with decreased activities, and thus may contribute to physical inactivity and consequently low functional capacity of this population. Therefore, poor adherence to regular physical activity is another important point to be considered by patients undergoing hemodialysis. ${ }^{11,33}$ Of the patients in our study, $86.7 \%$ declared themselves physically inactive, and this sedentary lifestyle has been associated with muscle and cardiovascular limitations, both as a consequence of the disease and hemodialysis sessions. $^{8}$

Physically active patients (13.3\%) achieved better performance in the vitality and functional capacity domains in our study. The relationship between physical activity practice and quality of life has also been widely studied in CKD patients, showing beneficial effects in several aspects. ${ }^{23,34-37}$ In a systematic review, Afsar et al. ${ }^{34}$ analyzed 38 studies addressing the effects of exercise on physical function, cardiopulmonary performance and quality of life in dialysis and non-dialysis patients, finding good results after exercise programs. The authors point out that exercise-associated clearance of uremic toxins increased muscle, cardiovascular and skeletal performance in dialysis patients, with a positive impact on quality of life. Given these findings, the importance of implementing cardiorespiratory/metabolic rehabilitation programs aimed at this population is emphasized in order to reduce musculoskeletal and functional impacts, and promote improvement in quality of life, especially regarding physical aspects.

Some limitations need to be considered in the present study. Firstly, the heterogeneity of the sample in relation to clinical aspects and sex, which may have influenced the absence of correlations/associations between variables, even with the use of categorization strategies. However, this behavior has also been observed in previous studies, which we can suggest is a characteristic of this population. Secondly, the practice of physical activity was self-reported by the research subjects, a limitation which may have been mitigated by the fact that most did not practice any type of exercise. And finally, the use of a global quality of life questionnaire. However, although there is a specific questionnaire for CKD and validated in Brazil, we decided to use the SF-36 because it is also widely used in patients undergoing hemodialysis. ${ }^{38} \mathrm{We}$ suggest future studies to be carried out using specific questionnaires for CKD (i.e., KDQOL), at different times (before, during and after) hemodialysis, and with longterm follow-up to better understand the impact of HD on this population. We also emphasize that evaluative instruments should be adopted that directly quantify the level of physical activity and correlate it with the domains of quality of life and maximum respiratory pressures, as well as characterize the sample in its socioeconomic components.

\section{Conclusion}

CKD patients undergoing hemodialysis had reduced MEP in relation to predicted and MIP impaired in men with increased CKD time and in women alone, but the clinical relevance of this finding is uncertain. In addition, they also had worse quality of life in the physical limitation domain with greater impairment among men, and mental health represented the domain of better quality of life. Those who practiced self-reported physical activity obtained better results in the domains of vitality (total sample) and functional capacity (males), when compared to sedentary patients.

\section{Authors' contributions}

JSS, TSS and CFRS were responsible for the conception of the study; FS and TO, for the conception and design. Analysis and interpretation of data were realized by JSS, TSS, CFRS and TO, and the writing of the manuscrit by JSS, TSS and TO. FS was responsible for reviewing the manuscript, and TO for approving the version to be published.

\section{References}

1. Nelson AJ, Raggi P, Wolf M, Gold AM, Chertow GM, Roe MT. Targeting vascular calcification in chronic kidney disease. JACC Basic Transl Sci. 2020;5(4):398-412. DOI

2.Medeiros AIC, Fuzari HKB, Rattesa C, Brandão DC, Marinho PEM. Inspiratory muscle training improves respiratory muscle strength, functional capacity and quality of life in patients with chronic kidney disease: a systematic review. J Physiother. 2017;63(2):76-83. DOI 
3. Vanholder R, Laecke SV, Glorieux G, Verbeke F, CastilloRodriguez E, Ortiz A. Deleting death and dialysis: conservative care of cardio-vascular risk and kidney function loss in chronic kidney disease (CKD). Toxins (Basel). 2018;10(6):237. DOI

4. Fassbinder TRC, Winkelmann ER, Schneider J, Wendland $J$, Oliveira OB. Functional capacity and quality of life in patients with chronic kidney disease in pre-dialytic treatment and on hemodialysis: a cross sectional study. J Bras Nefrol. 2015;37(1):47-54. DOI

5. Figueiredo PHS, Lima MMO, Costa HS, Gomes RT, Neves CDC, Oliveira ES, et al. The role of the inspiratory muscle weakness in functional capacity in hemodialysis patients. PloS One. 2017;12(3): e0173159. DOI

6.Souza VA, Oliveira D, Mansur HN, Fernandes NMS, Bastos MG. Sarcopenia in chronic kidney disease. J Bras Nefrol. 2015;37(1):98-105. DOI

7. Cury JL, Brunetto AF, Aydos RD. Negative effects of chronic kidney failure on lung function and functional capacity. Rev Bras Fisioter. 2010;14(2):91-8. Full text link

8. Pomidori L, Lamberti N, Malagoni AM, Manfredini F, Pozzato

E, Felisatti $M$, et al. Respiratory muscle impairment in dialysis patients: can minimal dose of exercise limit the damage? A preliminary study in a sample of patients enrolled in the excite trial. J Nephrol. 2016;29(6):863-9. DOI

9. Wang B, Yin $Q$, Wang $Y Y$, Tu $Y$, Han $Y$, Gao $M$, et al. Diaphragmatic dysfunction associates with dyspnoea, fatigue, and hiccup in haemodialysis patients: a cross-sectional study. Sci Rep. 2019;9(1):19382. DOI

10. Rosa CSC, Nishimoto DY, Freitas Jr IF, Ciolac EG, Monteiro HL. Factors associated with levels of physical activity in chronic kidney disease patients undergoing hemodialysis: the role of dialysis versus non-dialysis day. J Phys Act Health. 2017; 14(9):726-32. DOI

11. Valenzuela PL, Alba A, Pedrero-Chamizo R, Morales JS, Cobo F, Botella A, et al. Intradialytic exercise: one size doesn't fit all. Front Physiol. 2018;9:844. DOI

12. Miot HA. Sample size in clinical and experimental trials. J Vasc Bras. 2011;10(4):275-8. Full text link
13. Lloyd-Jones DM, Hong Y, Labarthe D, Mozaffarian D, Appel LJ, Van Horn L, et al. Defining and setting national goals for cardiovascular health promotion and disease reduction: the American Heart Association's strategic Impact Goal through 2020 and beyond. Circulation. 2010;121(4):586-613. DOI

14. Souza RB. Pressões respiratórias estáticas máximas. J Bras Pneumol. 2002t;28(Suppl 3):S155-65. Full text link

15. Neder JA, Andreoni S, Lerario MC, Nery LE. Reference values for lung function tests. II. Maximal respiratory pressures and voluntary ventilation. Braz J Med Biol Res. 1999;32(6):71927. DOI

16. Ciconelli RM, Ferraz MB, Santos W, Meinão I, Quaresma MR. Brazilian-Portuguese version of the SF-36. A reliable and valid quality of life outcome meansure. Rev Bras Reumatol. 1999;39(3):143-50. Full text link

17. Schardong JT, Lukrafka LJ, Garcia DV. Avaliação da função pulmonar e da qualidade de vida em pacientes com doença renal crônica submetidos à hemodiálise. J Bras Nefrol. 2008;30(1):40-7. Full text link

18. Roxo RS, Xavier VB, Miorin LA, Magalhães AO, Sens YAS, Alves VLS. Impact of neuromuscular electrical stimulation on functional capacity of patients with chronic kidney disease on hemodialysis. J Bras Nefrol. 2016;38(3):344-50. DOI

19. Rocha CBJ, Araújo S. Evaluation of maximum respiratory pressures in chronic renal patients at the pre and post hemodialysis moment. J Bras Nefrol. 2010;32(1):105-11. DOI

20. Bennett PN, Capdarest-Arest N, Parker K. The physical deterioration of dialysis patients-lgnored, ill-reported, and illtreated. Semin Dial. 2017;30(5):409-12. DOI

21. Jatobá JPC, Amaro WF, Andrade APL, Cardoso FPF, Monteiro AMH, Oliveira MAM. Avaliação da função pulmonar, força muscular respiratória e teste de caminhada de seis minutos em pacientes portadores de doença renal crônica em hemodiálise. J Bras Nefrol. 2008;30(4):280-7. Full text link

22. Kovelis D, Pitta F, Probst VS, Peres CPA, Delfino VDA, Mocelin $A J$, et al. Pulmonary function and respiratory muscle strength in chronic renal failure patients on hemodialysis. J Bras Pneumol. 2008;34(11):907-12. DOI 
23. Manfredini F, Mallamaci F, D'Arrigo G, Baggetta R, Bolignano $D$, Torino $C$, et al. Exercise in patients on dialysis: A multicenter, randomized clinical trial. J Am Soc Nephrol. 2017; 28(4):125968. DOI

24. Rhee SY, Song JK, Hong SC, Choi JW, Jeon HJ, Shin DH, et al. Intradialytic exercise improves physical function and reduces intradialytic hypotension and depression in hemodialysis patients. Korean J Intern Med. 2019;34(3):588-98. DOI

25. Dipp T, Macagnan FE, Schardong J, Fernandes RO, Lemos LC, Plentz RDM. Short period of high-intensity inspiratory muscle training improves inspiratory muscle strength in patients with chronic kidney disease on hemodialysis: a randomized controlled trial. Braz J Phys Ther. 2020;24(3):280-6. DOI

26. Figueiredo PHS, Lima MMO, Costa HS, Martins JB, Flecha $\mathrm{OD}$, Gonçalves PF, et al. Effects of the inspiratory muscle training and aerobic training on respiratory and functional parameters, inflammatory biomarkers, redox status and quality of life in hemodialysis patients: A randomized clinical trial. PLoS One. 2018;13(7):e0200727. DOI

27. Broers NJH, Martens RJH, Canaud B, Cornelis T, Dejagere $T$, Diederen NMP, et al. Health-related quality of life in end-stage renal disease patients: the effects of starting dialysis in the first year after the transition period. Int Urol Nephrol. 2018;50(6):1131-42. DOI

28. Wyld MLR, Morton RL, Clayton P, Wong MG, Jardine M, Polkinghorne K, et al. The impact of progressive chronic kidney disease on health-related quality-of-life: a 12-year community cohort study. Qual Life Res. 2019;28(8):2081-90. DOI

29. Johansson L, Fouque D, Bellizzi V, Chauveau P, Kolko A, Molina P, Sezer S, Ter Wee P, Teta D, Carrero JJ. As we grow old: nutritional considerations for older patients on dialysis. Nephrol Dial Transplant. 2017;32(7):1127-36. DOI

30. Qiu Z, Zheng K, Zhang H, Feng J, Wang L, Zhou H. Physical Exercise and Patients with Chronic Renal Failure: A MetaAnalysis. Biomed Res Int. 2017;2017:7191826. DOI
31. Tchape ODM, Tchapoga YB, Atuhaire C, Priebe G, Cumber SN. Physiological and psychosocial stressors among hemodialysis patients in the Buea Regional Hospital, Cameroon. Pan Afr Med J. 2018;30:49. DOI

32. Costa PB, Vasconcelos KFS, Tassitano RM. Qualidade de vida: pacientes com insuficiência renal crônica no município de Caruaru, PE. Fisioter Mov. 2010;23(3):461-71. DOI

33. Cupisti A, D'Alessandro C, Fumagalli G, Vigo V, Meola M, Cianchi $C$, et al. Nutrition and Physical Activity in CKD patients. Kidney Blood Press Res. 2014;39(2-3):107-13. DOI

34. Afsar B, Siriopol D, Aslan G, Eren OC, Dagel T, Kilic U, et al. The impact of exercise on physical function, cardiovascular outcomes and quality of life in chronic kidney disease patients: a systematic review. Int Urol Nephrol. 2018;50(5):885-904. DOI

35. Soares KTA, Viesser MV, Rzniski TAB, Brum EP. Eficácia de um protocolo de exercícios físicos em pacientes com insuficiência renal crônica, durante o tratamento de hemodiálise, avaliada pelo SF-36. Fisioter Mov. 2011;24(1):133-40. DOI

36. Pu J, Jiang Z, Wu W, Li L, Zhang L, Li Y, et al. Efficacy and safety of intradialytic exercise in haemodialysis patients: a systematic review and meta-analysis. BMJ Open. 2019; 9(1):e020633. DOI

37. Huang M, Lv A, Wang J, Xu N, Ma G, Zhai Z, et al. Exercise training and outcomes in hemodialysis patients: systematic review and meta-analysis. Am J Nephrol. 2019; 50(4):240-54. $\mathrm{DOI}$

38. Chuasuwan A, Pooripussarakul S, Thakkinstian A, Ingsathit A, Pattanaprateep O. Comparisons of quality of life between patients underwent peritoneal dialysis and hemodialysis: a systematic review and meta-analysis. Health Qual Life Outcomes. 2020;18(1):191. Full text link 